Www.jmscr.igmpublication.org

Impact Factor (SJIF): 6.379

Index Copernicus Value: 79.54

ISSN (e)-2347-176x ISSN (p) 2455-0450

crossrefDOI: https://dx.doi.org/10.18535/jmscr/v6i8.193

Journal Of Medical Science And Clinical Research

IGM Publication

An Official Publication of IGM Publication

\title{
Clinico-Haematological and Biochemical Profile of Megaloblastic Anemia
}

Authors

\section{Roshan Mandloi ${ }^{1}$, Sonu Rawat ${ }^{2}$, Sarika Rawat ${ }^{3}$}

${ }^{1}$ Senior resident, Department of Medicine, NSCB Medical College, Jabalpur, Madhya Pradesh

${ }^{2}$ Resident Medical Officer, Department of Pathology, Gandhi Medical College, Bhopal, Madhya Pradesh

${ }^{3}$ Senior Resident, Dept of Obstetrics and Gynecology, NSCB Medical College, Jabalpur, Madhya Pradesh

Corresponding Author

\section{Dr Sonu Rawat}

Email: sonurawat0308@gmail.com

\begin{abstract}
Background: Megaloblastic anemia (MA) is a distinct type of anemia characterized by macrocytic RBCs and typical morphological changes in RBC precursors. The RBC precursors are larger than the cells of same stage and exhibit disparity in nuclear-cytoplasmic maturation. Basic underlying pathogenetic mechanism in MA is deficiency of folic acid (FA) and/or vitamin B12 at the cellular level with resultant impairment of DNA synthesis. In developing countries, most cases of MA result from nutritional deficiency of these micronutrients.
\end{abstract}

Aims and Objectives

1. To correlate and compare the clinico-hematological and biochemical profile of megalo blastic anemia.

2 .To find out the clinical and haematological features of severe anemia.

Materials and Methods: This descriptive study included 60 cases of megaloblastic anemia to evaluate Association of biochemical profile of megaloblastic anemia. Data collected from case files, patient history, clinical profile, Peripheral blood findings, haematological parameters and biochemical parameters.

Results: In our study, megaloblastic anaemia was mostly found in <5 years of age. The male to female ratio was 1.7:1 in our study. The most common clinical presentation was pallor \& generalised weakness (100\%) followed by easy fatigability (60\%), fever (28.3\%), altered behaviour (13.3\%) and tingling (16.9\%) are found. Bleeding (18.3\%), itching and red spots $(6.6 \%)$ are found in patients having thrombocytopenia. Megaloblastic anemiawas found mostly in vegetarians (71.6\%). The mean haemoglobin was $7.3 \mathrm{gm} / \mathrm{dl}$. Splenomegaly and hepatomegaly were present in $21.3 \%$ and $26.6 \%$ respectively. There was complete correlation between parameters in 27/60 (45\%) cases only.

Conclusion: Inadequate dietary intake, overcooking of our food and poor absorption contributing high prevalence of megaloblastic anemia.

Keywords: Megaloblastic Anemia, Folic acid, Vitamin B-12.

\section{Background}

Anemia is defined as a reduction of the total circulating red cell mass below normal limits. Anemia reduces the oxygen carrying capacity of blood, leading to tissue hypoxia. ${ }^{1}$
In the United States, the prevalence of anemia in population studies of healthy, non-pregnant people depends on the $\mathrm{Hb}$ concentration chosen for the lower limit of normal values. The World Health Organization (WHO) chose $12.5 \mathrm{~g} / \mathrm{dl}$ for both 
adult males and females. ${ }^{2}$ In the United States, limits of $13.5 \mathrm{~g} / \mathrm{dl}$ for men and $12.5 \mathrm{~g} / \mathrm{dl}$ for women are probably more realistic. ${ }^{3}$ In India, anemia is considered below $11.0 \mathrm{~g} / \mathrm{dl}$ in females and $13.0 \mathrm{~g} / \mathrm{dl}$ in males. ${ }^{2}$ In developing countries, about $40 \%$ of preschool children and $50 \%$ of pregnant women are estimated to be anaemic. Anemia affects approximately $17 \%$ in industrialized countries. Nutritional megaloblastic anemia in children occurs commonly among under-nourished or malnourished societies of tropical and subtropical countries. ${ }^{2}$

Megaloblastic Anemia is one of the important causes of anemias in children. It is not an infrequent entity in poor socioeconomic condition. ${ }^{3}$ The majority of anaemia cases in children are nutritional with megaloblastic anaemia being a major contributory factor. It is an important health problem in almost all the developing countries of the world and invariably a common accompanying feature of protein energy malnutrition. ${ }^{4}$

Megaloblastic anemia (MA) is a distinct type of anemia characterized by macrocytic RBCs and typical morphological changes in RBC precursors. The RBC precursors are larger than the cells of same stage and exhibit disparity in nuclearcytoplasmic maturation. ${ }^{4}$

Vitamin B12 deficiency may be due to inadequate intake, food-bound vitamin B12 malabsorption, lack of intrinsic factor or parietal cells, ileal malabsorption in patients with enteritis or ileal resection, biologic competition including bacterial overgrowth and tapeworm infestation. ${ }^{5}$

Megaloblastic anemia resulting from impaired DNA synthesis is characterized by the presence of megaloblastic red cell precursors in the bone marrow and also in the blood. Megaloblast have a characteristic chromatin pattern and increased cytoplasm as a result of asynchrony of nuclear and cytoplasmic maturation with a relatively immature nucleus for the degree of cytoplasmic hemoglobinization. ${ }^{6}$ Hematological findings are nuclear hypersegmentation of neutrophils, macroovalocytes, increased (>100fl) MCV, tear drop cells, Howell jolly bodies, cabot ring basophilic stippling and nucleated red cells are seen. ${ }^{7}$ Certain races and ethnic groups have an increased prevalence of genetic factors associated with certain anemias. Race is a factor in nutritional anemias and anemia associated with untreated chronic illnesses eg. malaria, tuberculosis, acquired immunodeficiency syndrome. ${ }^{8}$ This descriptive study was planned to correlate and compare the clinico-hematologic, biochemical parameters with diagnosed cases as megaloblastic anemia on peripheral smear finding.

\section{Materials and Methods}

This descriptive study period was conducted in the Department of Pathology, Gandhi Medical College, Bhopal. 60 Patients who were diagnosed as megaloblastic anemia on peripheral blood smear and biochemical investigations.

The study included all cases of anemia having hemoglobin less than $11 \mathrm{gm} / \mathrm{dl}$. Grading of Anemia.

The patients were then grouped as mild (10-10.9 gm \%), moderate (7-9.9 gm \%) and severe ( $<7 \mathrm{gm}$ $\%)$ anemia based on their initial hemoglobin level. Patients were recorded in proforma, including detailed history, clinical profile, haematological parameters and biochemical parameters.

Blood sample was collected for complete blood counts using automated 3 \& 5 part mindray counter machine. Leishman stained smears of Peripheral blood smear were examined. Estimation of Biochemical Parameters Blood sample in a plain vial was collected. After centrifugation, the clear supernatant serum was collected. It was used for the estimation of Serum vitamin B12, folate by the Chemi-luminescence method. 


\section{Results}

Table 1 Age and sex distribution of study subjects

\begin{tabular}{|l|c|c|c|c|}
\hline Age Group & Male & & Female & \\
\hline & $\mathrm{N}$ & $\%$ & $\mathrm{~N}$ & $\%$ \\
\hline$\leq 5$ years & 13 & $33.2 \%$ & 8 & $36.3 \%$ \\
\hline $6-15$ years & 9 & $26.3 \%$ & 5 & $22.7 \%$ \\
\hline 16-25 years & 6 & $15.7 \%$ & 2 & $9.0 \%$ \\
\hline $25-35$ years & 8 & $21.0 \%$ & 4 & $18.1 \%$ \\
\hline 35 years & 2 & $5.2 \%$ & 3 & $13.6 \%$ \\
\hline Total & $\mathbf{3 8}$ & $\mathbf{1 0 0 \%}$ & $\mathbf{2 2}$ & $\mathbf{1 0 0 \%}$ \\
\hline
\end{tabular}

Maximum number of cases $(35 \%)$ were found in $<5$ years of age group (Age range: upto 50 years) with male predominance.

Table 2. Distribution of study subjects according to their Dietary habit

\begin{tabular}{|l|c|c|}
\hline Dietary Habit & N & Percentage \\
\hline Vegetarian & 43 & $71.6 \%$ \\
\hline Non vegetarian & 17 & $28.3 \%$ \\
\hline Total & $\mathbf{6 0}$ & $\mathbf{1 0 0 \%}$ \\
\hline
\end{tabular}

Maximum number of cases was vegetarian $-71.6 \%$.

Table 3 Distribution of study subjects according to their Religion

Maximum patients were Hindu.

\begin{tabular}{|l|c|c|}
\hline Religion & $\mathbf{N}$ & Percentage \\
\hline Hindu & 46 & $76.6 \%$ \\
\hline Muslim & 14 & $23.3 \%$ \\
\hline Total & $\mathbf{6 0}$ & $\mathbf{1 0 0 \%}$ \\
\hline
\end{tabular}

Table 4. Distribution of Clinical symptoms and signs in study subjects

\begin{tabular}{|l|c|c|}
\hline Clinical Features & N & Percentage \\
\hline Paleness of skin & 60 & $100 \%$ \\
\hline Generalized weakness & 60 & $100 \%$ \\
\hline Easy fatigability & 24 & $60.0 \%$ \\
\hline Fever & 17 & $28.3 \%$ \\
\hline altered behavior & 8 & $13.3 \%$ \\
\hline Tingling, numbness & 11 & $16.9 \%$ \\
\hline Bleeding from skin \& subcutaneous tissue & 5 & $18.3 \%$ \\
\hline Itching, red spots & 4 & $6.6 \%$ \\
\hline
\end{tabular}

Maximum no. of cases present with symptoms of pallor \& generalized weakness $(100 \%)$ followed by easy fatigability $(60 \%)$, fever $(28.3 \%)$, altered behaviour $(13.3 \%) \&$ tingling sensation $(16.9 \%)$ were found in vitamin B12 deficiency. Bleeding (18.3\%), itching and red spots (6.6\%) were attributed due to thrombocytopenia.

Table 5 Radiological findings in study subjects

\begin{tabular}{|l|c|c|}
\hline Radiological Findings & N & Percentage \\
\hline Splenomegaly & 13 & $21.6 \%$ \\
\hline Hepatomegaly & 16 & $26.6 \%$ \\
\hline
\end{tabular}

In our study, cases of splenomegaly were $21.6 \%$ and cases of hepatomegaly were $26.6 \%$.

Table 6. Distribution of study subject according to severity of anemia

\begin{tabular}{|l|c|c|c|c|c|c|}
\hline Hemoglobin Level & Male & & Female & & Total & \\
\hline$<7$ gm\% & $\mathrm{N}$ & $\%$ & $\mathrm{~N}$ & $\%$ & $\mathrm{~N}$ & $\%$ \\
\hline $7-9.9 \mathrm{gm} \%$ & 20 & $33.3 \%$ & 13 & $21.6 \%$ & 33 & $55 \%$ \\
\hline $10-10.9 \mathrm{gm} \%$ & 13 & $21.6 \%$ & 7 & $11.6 \%$ & 20 & $33.3 \%$ \\
\hline Total & 5 & $8.3 \%$ & 2 & $3.3 \%$ & 7 & $11.6 \%$ \\
\hline
\end{tabular}


Severe anemia $55 \%$, moderate anemia $33.3 \%$ and mild anemia $11.6 \%$ with male predominance. In males, $33.3 \%$ and in females, $21.6 \%$ of severe anemias were found.

Table 8 Correlation of biochemical Parameters

\begin{tabular}{|l|c|c|c|c|c|c|}
\hline Parameter & Low & & Normal & & High & \\
\hline & $\mathrm{N}$ & $\%$ & $\mathrm{~N}$ & $\%$ & $\mathrm{~N}$ & $\%$ \\
\hline S. folate & 32 & 53.3 & 23 & 38.3 & 5 & 8.3 \\
\hline S. B12 & 27 & 45 & 30 & 50 & 3 & 5 \\
\hline
\end{tabular}

S. vitamin B-12 is decreased in $45 \%$ cases and folic acid is decreased in 53.3\% cases, which correlates with PBS and biochemical parameters.

\section{Discussions}

In our study period of 8 months, there were $52.4 \%$ cases of anemia. In india, dietary habits are influenced and affected by differences in religion, cultural and socioeconomic status. Majority of patients in our study belonged to low socioeconomic status.

The mean age of our patients is 9 years (Age range: 1 - 50 years). $35 \%$ of patients in our study were less than 5 years with male: female ratio1.7:1. Sairaperwez et $\mathrm{al}^{9}$ reported the mean age as 38.9 years (1-80 years), peak age group was $35-50$ years. The male to female ratio was 1:1. Jagdish Chandra et $\mathrm{al}^{4}$ reported peak age less than 2 years (6 months-12 years), male to female ratio was 1.04:1. Male predominance in our study could be due to social patterns in our society as males get more attention in Indian families.

Low socio-economic class contributes significantly to anemia and most of the children belonged to class III and IV socio-economic class, i.e., $57.7 \%$ and $31.3 \%$ respectively. Which is similar to study of Sunil Gomber et al ${ }^{3}$

This findings similar to Saira Perwaiz et $\mathrm{al}^{9}$ and Pogura Nagarjuna et al ${ }^{10}$ who reported anemia in $85 \%$ and $60 \%$ vegetarians respectively. In our study, vegetarians are 71.6. It may be due to religious and social issues.

The most common clinical presentation besides pallor and generalised weakness which were present in all cases, where easy fatigability $(60 \%)$ and Fever (28.3\%).

Hyper pigmentation of dorsum of hands and fingers are noticed in only two children. 5 out of 60 cases $(18.3 \%)$ presented with bleeding manifestations. The bleeding was mainly into the skin and subcutaneous tissue. Which is similar to Sunil Gomber et $\mathrm{al}^{3}$

The mean hemoglobin in our study was $7.3 \mathrm{~g} / \mathrm{dl}$. Saira et $\mathrm{al}^{9}$ reported the mean hemoglobin was $6.8 \mathrm{~g} / \mathrm{dl}$. In Sunil Gomber et al, ${ }^{3}$ Jagdish Chandra et $\mathrm{al}^{4}$ reported, haemoglobin was $5.32 \mathrm{~g} / \mathrm{dl}$ and $5.65 \mathrm{~g} / \mathrm{dl}$.

Morphological findings: Peripheral smear showed predominantly macrocytes, macroovalocytes and pear shaped poikilocytes. Hyper segmentation of large sized neutrophils was seen in all cases. Which is similar to Pogura Nagarjuna et $\mathrm{al}^{10}$ and Sunil Gomber et $\mathrm{al}^{3}$

The mean MCV in our study is 105. E. J. WATSON-WILLIAMS AND A. F. FLEMING are reported the MCV is 102 which is similar our study. ${ }^{11}$

In the present study almost all cases had PCV value of less than $34 \%$. Which is similar to Pogura Nagarjuna et $\mathrm{al}^{10}$ is repoted mean PCV is $30 \%$.

In our study, splenomegaly and hepatomegaly were present in $21.6 \%$ and $26.6 \%$. Amieleena Chhabra et al $^{12}$ reported splenomegaly and hepatomegaly were $28.8 \%$ and $53.3 \%$. Sunil Gomber et $\mathrm{al}^{3}$ reported splenomegaly and hepatomegaly were $21 \%, 66 \%$ respectively. Splenomegaly was present in most of the moderate to severe anemic and thrombocytopenic patients. It is generally believed that as severity of anemia increases, thrombocytopenia develops followed by neutropenia.

Megaloblastic anemia presents with protean manifestations as experienced in our study. Bleeding most likely due to thrombocytopenia was noticed in $18.3 \%$ of patients. 
Thrombocytopenia is believed to be due to impaired DNA synthesis resulting in ineffective thrombopoiesis. $^{3}$

Biochemical parameters: B12 deficiency was detected in 27 cases $(<80 \mathrm{pg} / \mathrm{ml})$, folic acid in 32 cases and 5 case had pure folate deficiency $(<3$ $\mathrm{ng} / \mathrm{ml})$. There was complete correlation between parameters in 27/60 (45 \%) cases. Which is similar to Sunil Gomber et $\mathrm{al}^{3} \quad$ B12 deficiency was detected in 5 cases $(<80 \mathrm{pg} / \mathrm{ml})$, dual deficiency of B12 and folic acid in 2 cases and 1 case had pure folate deficiency $(<3 \mathrm{ng} / \mathrm{ml})$.

All cases shows megaloblastosis on peripheral blood smear. Pancytopenia was reported in $14.6 \%$ cases in our study. Which is similar to Sunil Gomber et $\mathrm{al}^{3}$ Megaloblastic anemia is an important cause of cytopenias.

Role of malabsorption and within country population migration towards urban areas contributing to diminished endogenous B12 synthesis needs to be elucidated.

Serum Folate/Vitamin-B12 levels are known to be highly labile, to the extent that a low serum folate concentration can be rapidly normalized shortly after consumption of a single nutritious folate rich meal. Clinically, it is important to know whether the anemia is due to folate or vitamin B12 or combined deficiency, so that the appropriate treatment may be given.

\section{Conclusion}

1. Inadequate dietary intake, overcooking of our food and poor absorption contributing high prevalence of megaloblastic anemia.

\section{References}

1. Vinay kumar, Abdul k.Abbas, Jon C.Aster, Robbins and Cotran, Pathologic basis of Disease, South asia edition. 2015. ISBN978-1-4557- 2613-4 Volume 1 page no. 629.

2. Erin McLean1, Mary Cogswell2, Ines Egli3, Daniel Wojdyla4 and Bruno de Benoist1, Worldwide prevalence of anaemia, WHO Vitamin and Mineral
Nutrition Information System, 1993-2005.

1Department of Nutrition for Health and Development, World Health Organization, 20 Avenue Appia, CH-1211, Geneva 27, Switzerland: March 2008

3. Gomber S, Kela K, Dhingra N (1998) Clinico-hematological profile of megaloblastic anemia.1998. Indian Pediatr 35: 55-58. 70 Volume 35- January 1998.

4. Jagdish Chandra, Megaloblastic Anemia: Back in Focus, Department of Pediatrics, Lady Hardinge Medical College, and Kalawati Saran Children's Hospital, New Delhi, India, [Indian J Pediatr 2010; 77 (7) : 795-799]

5. Andy Sun1,2, Julia Y.-F. Chang1,2, YiPing Wang1,2, Shih-Jung Cheng1,2, HsinMing Chen1,2,3, Chun-Pin Chiang1,2,3. Do all the patients with vitamin B12 deficiency have pernicious anemia? 2Department of Dentistry, National Taiwan University Hospital, College of Medicine, National Taiwan University, Taipei, Taiwan; J Oral Pathol Med (2016) 45:23-27

6. Barbara J. Bain, Imelda Bates, Mike A. Laffan, S. Mitchell Lewis, Dacie and Lewis, Practical Haematology, 2014. Eleventh edition. Chapter 10, page no. 204

7. Dr.Tejindarsingh MD, FICP, FISHTM, Atlas and text of Hematology, Department of Pathology, Maulana Azad Medical College, New Delhi. 2014. Third edition. ISBN-978-81-7739-413-9. Chapter 3 Page no. 95.

8. R Athar, Y Khonglah, V Raphael, A Pal, K G Lynrah. Clinico-Hematologic And Biochemical Profile Of Dimorphic Anemia with Bone Marrow Study. The Internet Journal of Laboratory Medicine. 2014 Volume 6 Number 1.

9. Saira PI, Ghulam Nabi K, Saleem PI. (2009) Vitamin B12 deficiency - a major cause of megaloblastic anemia in patients attending a tertiary care hospital. Journal 
of Ayub Medical College Abbottabad 21(3):92-94.

10. Dr. Pogula Nagarjuna Reddy, Dr. Vinaya Swami P.M Clinical hematological and bone marrow study of severe anaemia. Department of Pathology, J.J.M. Medical College Davanagere, Karnataka, India. Indian Journal of Basic and Applied Medical Research; March 2015: Vol.-4, Issue- 2, P. 292-297

11. E. J. Watson-Williams, NIB.,B.Chir., M.R.C.P: Senior Lecturer, Manchester University Department of Clinical Hematology, Manchester, Engkind. A. F. FLEMING, B.CLIN: Senior Registrar, Sub-Department of Hematology, University College Hospital, Ibadan, Nigeria.

12. Amieleena Chhabra, Vipan Chandar, Alpa Gupta, Harish Chandra, Department of Paediatrics and Department of Pathology, Himalayan Institute of Medical Sciences, Jo Journal, Indian Academy of Clinical Medicine 1 Vol. 13, No. 31 JulySeptember, 2012lly Grant, Dehradun, Uttarakhand, JIACM 2012; 13(3): 195-7. 